\title{
UNA APROXIMACIÓN A LA TEMÁTICA DEL TEATRO DE MANUEL LINARES RIVAS
}

\author{
AN APPROACH TO THE THEMES OF MANUEL LINARES RIVAS’ PLAYS
}

\author{
Gabriel Ares Cuba \\ Universidade da Coruña \\ garescuba@yahoo.es
}

Fecha de recepción: 21-10-2019

Fecha de aceptación: 20-12-2019

\section{RESUMEN}

Se estudia la temática de diez obras de Manuel Linares Rivas teniendo en cuenta su contexto socio-histórico. Se intenta demostrar, al menos provisionalmente, que Linares Rivas se centra en temas propios de una burguesía radical que reniega del statu quo y critica las miserias de los grupos más marginados. De esta manera, su teatro se aproximaría a una corriente novadora y rupturista del teatro español del primer tercio del siglo XX.

PALABRAS ClAVE: historia del teatro; sociología del teatro; teatro social; teatro de preguerra; teatro burgués

\section{AbStract}

This article analyzes the topics of ten plays by Manuel Linares Rivas, taking into account the socio-historical context. I try to demonstrate, at least provisionally, that Linares Rivas focuses on issues of a radical bourgeoisie that denies the status quo and criticizes the miseries of the most marginalized groups. In this way, his dramas would approach a radically new theatrical movement, developing in the first three decades of the twentieth century. 
KEY WORDS: drama history; sociology of drama; social drama; pre-war drama; bourgeois drama

\section{Introducción}

Manuel Linares Rivas forma parte de aquella nómina de autores que, a pesar de haber podido presumir de relevancia social y artística en su época, hoy en día no representa más que una anécdota en las historiografías académicas más canónicas. Al autor gallego le acompaña un estigma, que es el ser considerado un continuador de la técnica teatral de Jacinto Benavente ${ }^{1}$. José García López (García, 1962), Max Aub (Aub, 1974) y Gerald Brown (Brown, 1974) son los primeros en realizar esta filiación, que será discutida unos años más tarde por Ángel Berenguer (Berenguer, 1982). A él se le debe el primer intento por diferenciar las distintas corrientes teatrales de este periodo: teatro restaurador (representante de la perspectiva de la nobleza y que aboga por restaurar los valores tradicionales), teatro innovador (perspectiva de la burguesía acomodada en connivencia con la nobleza y el clero, pero presentando intentos de modernización hacia el liberalismo mediante nuevas técnicas teatrales) y teatro novador (visión de la burguesía radical en consonancia con los intereses pequeñoburgueses y obreros, igualmente mediante la modernización dramatúrgica). El catedrático sitúa a Benavente dentro del teatro innovador, pero a Linares Rivas, dentro del teatro novador, quedando alineado con autores como Galdós, Dicenta, Guimerá, Cortiella o Gómez de la Serna. Sin embargo, Francisco Ruiz Ramón (Ruiz, 1986) recupera la visión original.

A partir de aquí, comienza una polémica todavía hoy sin resolver. Autores como Alfredo Rodríguez López-Vázquez (Rodríguez, 1995), Fidel López Criado (1996, 1997a, 1997b, 1998, 1999, 2001, 2009, 2014), Moisés Castro (2001a, 2001b, 2008), Rebeca Díez Figueroa (Díez, 2001, 2005), Ana María García Freire (García Freire, 2001, 2005, 2009), José María Villarías Zugazagoitia (Villarías, 2001), o José Carlos Mainer (2010) apoyan la tesis de Berenguer y desvinculan a Linares Rivas de la tendencia innovadora. Al contrario, autores como Huerta Calvo (2003) o Lina Rodríguez Cacho (2009) apoyan los preceptos de Ruiz Ramón.

En este trabajo se intenta demostrar que los temas más importantes de la dramaturgia de Linares Rivas coinciden con las preocupaciones del teatro novador. A pesar de que nuestro dramaturgo pertenezca a la burguesía acomodada, sus postulados sociales atentan contra el statu quo que su propia clase ha venido creando desde comienzos de la sociedad liberal. Para ello, se intentará responder a las siguientes preguntas: ¿cuáles son los temas

${ }^{1}$ De hecho, en muchos de los manuales se sostiene que el tema central de su dramaturgia son las relaciones matrimoniales. Sin embargo, lo cierto es que solo constituyen un telón de fondo para ilustrar los problemas más profundos de la sociedad. Linares Rivas no es el único ni el primero en explotar este lugar común, también puede apreciarse en obras como Electra (1901), de Benito Pérez Galdós; Juan José (1895), de Joaquín Dicenta; La malquerida (1913), de Jacinto Benavente; o La señorita de Trevélez. (1916), de Carlos Arniches. Solamente en sus obras breves pueden encontrarse situaciones matrimoniales como tema central, aunque siempre atentando contra el decoro de la época. En todas ellas, el matrimonio es un obstáculo para la felicidad individual. 
que presenta el teatro de Linares Rivas?, ¿hasta qué punto se muestra comprometido con los colectivos más oprimidos? Se parte de la hipótesis de que Linares Rivas pertenece a la tendencia novadora, es decir, que propugna un modelo social más justo para reducir la desigualdad entre las clases sociales.

\section{Temas}

\section{a. Crítica a la opresión socioeconómica}

Este es el tema que más abunda dentro de la producción dramática de Manuel Linares Rivas, especialmente representado por la figura de la mujer dominada ${ }^{2}$. Hasta la proclamación de la II República, la legislación española consideraba que la mujer debía supeditarse a la voluntad del esposo ${ }^{3}$. Esta relación de dependencia económica se puede apreciar en Aire de fuera (1903), en La fuerza del mal (1914) o en La garra (1914).

La trama de Aire de fuera (1903) gira en torno a dos matrimonios: el primero, Baltasar y Carlota, representa la pareja ideal, pero solo en apariencia, ya que Carlota hace años que no se siente sexualmente satisfecha. El segundo, Magdalena y Juan, está roto emocionalmente y solo la ley burguesa obliga a Magdalena, que estaba viviendo en depósito en casa de Baltasar, a volver con Juan, su maltratador. Aquí, la opresión a la mujer no solo se traduce en represión social, sino también económica: sin dinero, no hay posibilidades de libertad, de ahí que Carlota pueda hacer efectivo su divorcio y Magdalena no ${ }^{4}$. En el artículo 68 del Código Civil de 1889 se estipula que, mientras se tramitan los papeles del divorcio, el

${ }^{2}$ Para Fidel López Criado, «la corrupción de un sistema político caciquil y oligárquico, el oscurantismo y la intransigencia religiosa, la hipocresía y el travestismo liberal de la gran burguesía, la desigualdad y la injusticia social, el europeísmo, la educación de la mujer, la marginación del campesino, el hambre y la pobreza, la explotación del trabajador y el emergente mundo capitalista, son algunas de las preocupaciones que de manera más insistente afloran en la dramaturgia linariana. Pero de manera especial, a Linares le duele la situación de la mujer, que utilizará como trasunto alegórico de la situación de la sociedad española de primer tercio de siglo» (López Criado, 2001: 275).

3 Según Ana Aguado (Aguado, 2011: 751-753), el Código Civil de 1889 reconocía el derecho del marido a administrar los bienes económicos del matrimonio y también a ser obedecido por su esposa. En el ámbito económico, solo se le reconocía a la mujer el derecho a comprar los bienes de consumo ordinario de la familia. Todo esto responde a un estereotipo cultural que relaciona la feminidad con el cuidado de la casa. De esta manera, surge el concepto de «ángel del hogar» para designar una supuesta excelencia de la mujer para encargarse de los asuntos domésticos. Esta concepción bebe en la tradición católica y viene a sustituir aquella supuesta inferioridad femenina surgida a comienzos de la sociedad liberal.

${ }^{4}$ La intención de la obra se resume muy bien en el siguiente pasaje: «CARLO.- Ha debido pasar muchas pruebas con la vida azarosa que lleva, y tal vez vuelva ansioso de paz [se refiere a Juan]. MAG.- Por Dios, no me digas, que eso sería más horrible aún... [...] ¿No habrá una ley que ampare a una mujer desesperada? CARLO.Las hacen los hombres y no se les ocurre pensar que en el cuerpo de una mujer pueda encontrarse un alma que sueñe o sufra. MAG.- Es una infamia lo que se hace conmigo: si fuera hombre emigraba de España; pero mujer y pobre, ¿dónde voy? CARLO.- Como tú hay centenares. MAG.- ¿Y qué hacen? CARLO.- Resignarse y ser mártires o sublevarse y... MAG.- Pero si yo quiero ser honrada. CARLO.- Entonces tienes que ser víctima» (Linares Rivas, 1999c: 1096-1097). Carlota, la mujer acomodada, incita a Magdalena, mujer pobre, a rebelarse contra la ley impuesta. Solo existen dos posibilidades: «Resignarse y ser mártires o sublevarse y...». 
juez establecería medidas cautelares como la separación temporal y una residencia provisional para que la mujer pudiese vivir sin miedo a sufrir penurias (depósito). Lo curioso es que la Ley de Enjuiciamiento Civil de 1881 solo asigna el depósito a mujeres en fase de separación, a menores y a incapaces (Vázquez de Prada, 2005). Los valores que sustentan esta obra se oponen a los expuestos en Flora o la Educación de una niña ${ }^{5}$.

La fuerza del mal (1914) aborda la historia de Candelas, una joven que quiere contraer nupcias con Ramoncho, pero se encontrará con la oposición de Justo, su padre. Salomé, la tía del muchacho, tendrá que intervenir para convencer a Justo de que sea más flexible y así evitar el odio eterno que le promete su hija. Durante los primeros años del siglo XX, el modelo de familia hereda la estructura del esquema decimonónico. En ella, el hombre ejerce de cabeza de familia. Es él quien trabaja y quien sustenta económicamente al resto. Esta idiosincrasia no se restringe al nivel moral, sino que también está contemplada en el Código Civil, ya que el estereotipo dominante de mujer la caracteriza como un ser irracional, demasiado emocional, poco inteligente y poco competitivo (Vázquez de Prada, 2005). Candelas decide oponerse a este estereotipo y romper el modelo de familia para enfrentarse a su padre, que ejerce su poder de varón-esposo-padre como un tirano ${ }^{6}$.

En La garra (1914), Antonio, el marqués de Montrove, y Sol de San Payo forman un matrimonio feliz hasta que se revela que el hombre había estado casado hace años en los Estados Unidos, hasta que se divorció justo antes de volver a España. Esto genera turbación en el núcleo familiar debido a la influencia que la Iglesia ejerce sobre los habitantes de Campanela, trasunto de Compostela. Solo el padre Muiños, párroco excomulgado por sus lecturas heterodoxas del dogma cristiano, es el único que ayudará al matrimonio a reconciliarse. Sin embargo, sus intentos fracasan, ya que los doctores de la Iglesia convencerán a Sol de que no puede alcanzar el perdón de Dios si mantiene la relación con el impío Antonio, lo cual provocará el suicidio del marqués. Esta opresión también afecta a Santa de San Payo y a Álvaro del Real. La muchacha fue abandonada por su marido tiempo atrás, pero no se atreve a establecer una relación con Álvaro, su amado, hasta que se cumpla legalmente el periodo para dar por fallecido a su esposo. No podrán consumar la relación ${ }^{7}$. Aquí cobra importancia la educación de la mujer. Santa y Sol han sido educadas bajo el yugo de la Iglesia y ahora no son capaces de alcanzar la felicidad, prefieren seguir aferradas al

\footnotetext{
${ }^{5}$ La influencia de esta obra fue tal que fue aprobada para la enseñanza en centros públicos por la Real Orden de 12 de mayo de 1888 (Castaño-Penalva, 2015: 64).

${ }^{6}$ Un momento de especial tensión en la obra se encuentra al final del acto primero, cuando Justo sospecha que su hija hubo mantenido relaciones sexuales con Ramoncho: «CAND. (Sonriente). ¿Papá? JUSTO. ¿Has ido tú al estudio de Ramoncho? ¡Responde! ¡¡Responde!! ¡¡¡Sí!!! (Le echa las manos al cuello, interviniendo Salomé y Santos; escapa Candelas por la derecha). SANT. ¿Tú estás loco? ¿Qué ibas a hacer? JUSTO. No lo sé, no lo sé... Pero hiciste bien quitándomela da las manos...» (Linares Rivas, 1999d: 1880)

${ }^{7}$ Linares Rivas expone la premisa de la obra en boca del padre Muíños: «P. MUI. —Pero eso no es. ¿Y sabe por qué no es? Porque son llamados a juzgarnos los que no sufren ni han sufrido nunca, del mal de que les pedimos remedio. [...], a mí me parece que debía de ser atinado y justo el que se formaran los Tribunales con personas que padecieran del mismo dolor que han de juzgar. [...], que al hambriento lo juzgue quien tenga hambre; al humillado quien no tenga puesto de soberbia; al perseguido quien no tenga hora tranquila...; y al que padece de amor y de pasión de amor, que no le juzgue ni lo sentencie quien ha renunciado voluntariamente a saber lo que es el amor» (Linares Rivas, 1999e: 1952).
} 
dogma, pues creen fervientemente que su alma será condenada si desobedecen los preceptos de los doctores ${ }^{8}$.

En obras más tardías como Fausto y Margarita (1935) o El error del capitán Rubín (1935), la mujer se presenta investida de derechos y solo amenazada por los valores trasnochados de algún personaje antagonista. La opresión en Fausto y Margarita afecta tanto al hombre como a la mujer, ya que proviene de Samuel, un banquero antiguo patrón de Fausto y, también, metonimia del capitalismo. La tarea del muchacho era realizar inversiones en bolsa y, por culpa de una mala decisión, Fausto pierde el dinero. Él acude a las arcas del banco para reponer la deuda, pero Samuel lo acusa de robo y le obliga a pagar más del doble. Samuel oprime en dos sentidos a Fausto: el primero, haciendo uso de la relación patrón-empleado. Samuel extorsiona a Fausto para que se declare culpable a cambio de no despedirlo y comprometerlo, así, a una deuda eterna. En este aspecto, se hace patente la escasez de principios éticos de Samuel, y por extensión, de todos los patrones, a quien no le importa la integridad de sus empleados. El segundo, mediante la relación rico-pobre. Si Fausto tuviese el mismo poder adquisitivo que Samuel no tendría ningún problema en reponer cualquier deuda impuesta o, incluso, asumir el despido. Pero Samuel sabe que Fausto depende de él, que sin ese trabajo no puede sobrevivir 9 .

En El error del capitán Rubín (1935) este tema no está tan presente como en el resto, pero sí es destacable la discusión entre Fabián y su mujer en el tercer acto ${ }^{10}$. Rubín es un joven capitán del Regimiento 25 de cazadores a caballo y está casado con Clotilde. Hace años que su esposa no siente nada por él, pero habían llegado al acuerdo de seguir compartiendo la casa y los gastos. Sin embargo, Rubín cree que tiene derecho moral y legal a someter a Clotilde bajo su voluntad. Ante las sospechas de que ella y Sartorio, su superior, mantenían relaciones sexuales, el capitán lo retará a duelo a muerte, pero será disuadido por sus

\footnotetext{
${ }^{8}$ López Criado recuerda que «las iras del clero y del sector más involucionista de la burguesía no se hicieron esperar en la recepción crítica de La garra. Pero tampoco se hicieron esperar las simpatías del proletariado y la pequeña burguesía. [...]. Desde entonces, La garra pasaría a ser símbolo de todo aquello que la España de la Santa Tradición debía combatir como nocivo, foráneo, antipatriótico y anticristiano en el teatro» (López Criado, 2009: $35)$.

${ }^{9}$ El siguiente extracto resume el conflicto de la acción dramática y perfila el punto de vista del autor: «MARG. [...] En esa Agencia de usted estaba Fausto hace años encargado de liquidar en las jugadas de Bolsa que usted hacía. [...] En una ocasión vio tan segura una jugada que se lanzó a operar algo también por su propia cuenta. SAMUEL. Solo que falló lo seguro... y no tuvo solución más rápida que la de echar mano a mi dinero. MARG. Con ánimo de restituir. [...], y entonces, aterrorizado, le propuso a usted dos soluciones: “ ¡perdóneme, y yo le trabajo sin ganar hasta que usted se desquite del último céntimo... o denúncieme por ladrón y aquí mismo me pego un tiro!’. [...] En ese papel consta además que la cantidad sustraída era de veinte mil duros. ¡OOcho veces más!! es decir, por parte de usted, una estafa» (Linares Rivas, 1999a: 382-383).

${ }^{10}$ Véase este fragmento, que muestra cómo Fabián se cree con el derecho de mandar sobre la voluntad de Clotilde, ya que ella supone para él su honra (concepto que proviene del siglo XVII), y, por tanto, una propiedad privada más, como si fuese un mueble o unas tierras: «FABIÁN. ¡Basta! La casa la debo llevar yo. Rompe tu amistad con esa persona. CLOTILDE. No. FABIÁN. ¡Te lo mando! CLOTILDE. Mala palabra has añadido. FABIÁN. Pues elige tú otra, pero atendiéndome. Renuncia, Clotilde. CLOTILDE. No. FABIÁN. (Desesperado). ¡¡Renuncia!! CLOTILDE. No. FABIÁN. ¿Pero no comprendes que una amistad en esas condiciones es una afrenta para mí? ¡Y para ti, eh, y para ti! CLOTILDE. Lo mío lo juzgo yo» (Linares Rivas, 1999b: 436).
} 
compañeros. Rubín, a pesar de ser joven, hereda los comportamientos machistas de generaciones anteriores.

Este tema adquiere la forma de liberación sexual y emocional en obras más breves como Lo posible (1905), En cuarto creciente (1905) o Clavito (1910). Seguramente esto sea debido a que el género breve no es el idóneo para analizar las estructuras económicas de la sociedad, ya que requieren acciones más ligeras y condensadas. En Lo posible (1905), un matrimonio de burgueses consiente mutuamente sus infidelidades. Son conscientes de que un matrimonio sin amor no significa nada, pero que la legislación es tan rígida que disolverlo por lo legal sería una pérdida de tiempo y de dinero. En En cuarto creciente (1905) abundan las referencias subconscientes para dar a entender encuentros sexuales entre todos los personajes, incluyendo criados y señores ${ }^{11}$. En Clavito, la protagonista decide quedar soltera a pesar de la presión social para salvaguardar los derechos que le serían privados en un matrimonio.

\section{b. Las «dos Españas»}

Este tema también está muy presente, sobre todo en sus primeras piezas. Es en Aire de fuera (1903) y en La garra (1914) donde más clara se ve esa dicotomía entre la España progresista, racional y científica; y la otra tradicionalista, pasional y oscurantista. En Aire de fuera (1903), Juan, el marido de Magdalena, representa esta España casta y anticuada que impide el avance social y la felicidad individual. Juan todavía cree que es legítimo exigir a la esposa que obedezca al marido. Por el contrario, Baltasar representa aquella otra con su carácter moderado y cosmopolita. Ante los reproches y reflexiones de Carlota acerca de su sexualidad y ansias de independencia, Baltasar accede a efectuar el divorcio en Bélgica sin abandonar su talante racional ${ }^{12}$. En La garra (1914), los doctores de la Iglesia, con sus normas cerradas e inhumanas, provocan la infelicidad de Sol de San Payo, del marqués de Montrove, de Santa de San Payo y de Álvaro del Real, generando el suicidio del marqués $^{13}$. Estos sucesos parecen recordar aquel epitafio de la tumba de los Ministerios en el

${ }^{11}$ Para profundizar en torno a los mensajes subconscientes en En cuarto creciente, véase el artículo de Alfredo Rodríguez López-Vázquez (1995).

${ }^{12}$ Muy pronto se presentan las notas biográficas de Baltasar: «BALT. En cuanto nuestra Carlota [hija] tenga edad para ello, estoy completamente decidido a enviarla fuera. GERA. Es una idea muy sensata. EDUA. En ti es natural esa preocupación. Te educaste en Bélgica, después dos años en los Estados Unidos, y has vuelto renegando de ser español. BALT. Renegando no; muy honrado de serlo; pero muy entristecido viendo que en mi patria se apedrean los trenes; que en las ciudades donde se bañan doscientas personas se quedan sin agua para beber los treinta y ocho o cuarenta mil restantes; viendo los campos cultivados como en el tiempo del rey Wamba». (Linares Rivas, 1999c: 1072-1073). Baltasar encarna el talante liberal progresista de Manuel Linares Rivas y, también, la intención de la obra.

${ }^{13}$ Este es el momento del suicidio de Antonio, el marqués de Montrove: «SOL. [...] Obedezco, madre. Decidle vosotros [al marqués] que se ausente de Campanela. ANTO. ¡Ya está clavada la garra! ¡Misericordia, padre Muiños! P. MUI. (Abrazándole). Resignación, hijo mío. ESPE. Dios nos asiste. Bendito y alabado sea. (Tiro). SOL. ¡Antonio! ¡Antonio! DOCT. ¡Se ha matado! ACIS. ¡Se ha matado! SOL. No; lo matáis vosotros. ANTO. Vosotros, que no dais más que una fórmula de muerte a la Humanidad que os pide una fórmula de vida... y la Humanidad quie... quie... SOL. ¡Antonio! ANTO. Quiere vivir... vi.. vir... vivir... (Muere)» (Linares Rivas, 1999e: 1966). 
cementerio de Madrid que Larra había transcrito: «aquí yace media España; murió de la otra media» (Larra, en línea) ${ }^{14}$.

c. Crítica al materialismo burgués

Se encuentra especialmente presente en Clavito (1910). Pelegrín quiere establecer una relación sentimental con la muchacha, y para ello procede como típicamente lo hacen los jóvenes burgueses y nobles del momento: mediante una muestra de poder económico. Clavito no se impresiona y prefiere seguir soltera a entrar en una dinámica de frivolidad matrimonial ${ }^{15}$. La sociedad burguesa espera de un hombre casamentero que tenga el suficiente poder económico como para seguir manteniendo los lujos de la mujer prometida en matrimonio. Además, esta comodidad económica permite condensar las riquezas de ambas familias en cada vez menos manos. Esto también se encuentra en La mala ley (1923). Aquí, Dionisio se opone a cosificar las relaciones amorosas y rechaza cualquier pretensión de conquistar a Cristina mediante ostentación de capital ${ }^{16}$. En este sentido, Dionisio es un personaje ejemplar, diametralmente opuesto a Pelegrín. Linares Rivas critica estas costumbres mecanizadas porque cosifican a las personas como meros engranajes sociales.

d. La tiranía

El tema de la tiranía está especialmente presente en La fuerza del mal (1914) y en La garra (1914), aunque también se puede rastrear en Aire de fuera (1914) a través del personaje de Juan. En La fuerza del mal (1914), Justo gobierna su casa con mano de hierro. De ahí que Candelas, su hija, deba recurrir a «la fuerza del mal», es decir, a la revolución, para poder vivir. Aunque se presente un escenario doméstico y aparentemente privado, lo cierto es que, como ya se dijo anteriormente, la estructura familiar de la época se estaba desmoronando precisamente por padres como Justo. Esto convierte el tema de la obra en una cuestión social que profundiza en torno a la relación entre padre e hija ${ }^{17}$. De igual manera, en $L a$

14 Antonio Castellón (1994) demuestra que la oposición entre estas dos comunidades es una preocupación que se manifiesta en un teatro de corte progresista, llámese teatro social, teatro novador o teatro radical. El mismo Benito Pérez Galdós lo muestra en 1905 con Amor y ciencia y también Joaquín Dicenta en Aurora (1902).

15 Clavito es lo suficientemente tajante como para cortar de raíz el cortejo: «PEL. A ver si de otra manera nos entendemos. ¿Quiere usted a Pelegrín?... y con Pelegrín lo que él tenga: casas, acciones... CLAV. Es demasiado rápida esa oferta para que pueda juzgarla más que como un arranque voluntarioso... PEL. Prométame usted al menos... CLAV. Nada». (Linares Rivas, 1910: 20).

${ }^{16}$ Este es el momento en que Dionisio explica a Cristina por qué le prestó a su padre el dinero y por qué no la acepta a ella como «amante»: «CRISTI. (Levantándose) ¿No quiere usted ya [relaciones]? DIONI. Ni quise antes. CRISTI. ¡Antes, sí! DIONI. No. Acepté en la apariencia y para vencer todo escrúpulo en la cuestión secundaria, infinitamente secundaria, de los intereses. ¿Hacía falta el dinero? Ahí va. Pero el hombre no hace falta..., y se va. [...]. La quiero a usted..., pero no quiero el sacrificio de usted. [...]Usted viene a mí, no por mí, sino por él. Es una gran razón para usted, pero no es razón ninguna para mí» (Linares Rivas, 1927: 71).

${ }^{17}$ La personalidad dictatorial de Justo ya se perfila desde su primera aparición en la escena II, cuando Marcelina y Justo «discuten» la lista de invitados para un baile: «JUSTO. Ahí te devuelvo la lista de las invitaciones que puedes mandar para el baile de este sábado. MARC. ¿Estaba bien? JUSTO. Sí, menos lo que he tachado. [...] Lo sentiré mucho, pero yo convido a quien me parece» (Linares Rivas, 1999d: 1857-1858). 
garra, los seguidores del dogma cristiano subyugan a Sol, a Santa, a Antonio y a Álvaro ${ }^{18}$. A los protagonistas no les quedará más remedio que rendirse y acatar las rígidas normas de Campanela si no quieren morir intentando ser libres. Este tema es una derivación de la opresión económica que se anotó más arriba, ya que sin poderes fácticos es imposible ejercer una tiranía.

e. Lo legal como motor de su dramaturgia

Lo legal en Linares Rivas supone una matriz temática. Su formación en derecho le permitió convertir en teatro los atrasos legales y sociales que la España de su momento sufría. El autor había analizado su sociedad desde el punto de vista de un jurista antes de comenzar a escribir, por eso hay que considerar estas reflexiones como la semilla de todos los temas de su dramaturgia. En Aire de fuera (1903) se apoya una modificación del código legal para garantizar la separación efectiva de los cónyuges en casos de malos tratos y abusos ${ }^{19}$. En La fuerza del mal (1914) aparece como tema secundario la división de la riqueza. Desde luego no se trata de una división de inspiración marxista, pero sí al menos socialdemócrata. Pedro, ex trabajador de Justo, queda en el paro debido a su ceguera y a cargo de su madre enferma. Al no poder hacer frente a los gastos, Justo le da limosnas, pero son insuficientes. Finalmente, decide tomarse la justicia por su mano y lo chantajea con unos documentos legalmente comprometedores. Se critica que Pedro tenga que llegar a recurrir a «la fuerza del mal» para alcanzar una vida digna, siendo posible redactar leyes que protejan a estos colectivos en riesgo de exclusión. En La garra (1914), se utiliza el divorcio para criticar la intoxicación del Código Civil por parte de una moral religiosa que lo hace dogmático y reaccionario $^{20}$. En La mala ley (1923), el conflicto entre los personajes tiene lugar por culpa de la ley de herencias, que obliga a un padre viudo a ceder los bienes de su difunta esposa a

18 Valga como ejemplo la primera aparición de Sol de San Payo. La joven decide estrenar un vestido de París para el baile, pero Esperanza, su madre, considera que es demasiado ligero. Lo llamativo es que Sol no se resiste a que su madre censure su vestimenta, lo cual proviene de la educación que recibió desde pequeña: «ÁLVA. Una monada de vestido. SOL. ¿Verdad? MARQ. Una maravilla. SOL. ¿Te gusta? TIRSO. ¿Qué dices tú? ESPE. Yo digo que me parece un atrevimiento escandaloso. SOL. ¡Alto! Con eso ya contábamos, mamá. (Entonada). ¡A mí, pajes y camaristas! (Adelantan Santa, Piluca y Mariquiña, con gasas, un acerico de alfileres y una cajita de imperdibles. Natural). Y tú dispondrás hasta dónde cubren. ESPE. Más subido. Más subido... Así. SOL. Traje de París, ya te convertiste en traje de Campanela. (Mientras Santa y las chicas transforman en vestido alto lo que fue un vestido escotado, siguen hablando)»(Linares Rivas, 1999e: 1931).

${ }^{19}$ Esto opina Baltasar sobre la ley del divorcio y, en general, todas las leyes: «EDUA. Pero las costumbres... BALT. Ya cambian ellas. EDUA. Y las leyes... BALT. Las podemos cambiar nosotros». (Linares Rivas, 1999c: 1076)

${ }^{20}$ En este extracto se muestra la opinión del marqués en torno a las leyes: «ANTO. [...] Mi madre, española, se casó con un americano del norte. En uno de los viajes que hicieron por España, nací yo, en Granada. Allí volví años después para seguir mi carrera de abogado, y una vez terminada fui a revalidar los estudios en Nueva York, naturalizándome súbdito americano para ejercer la profesión en el bufete de mi padre. (Pausa). Me casé muy joven. [...]Duró poco la paz... y a los dos años pedimos el divorcio. [...] Allí la ley civil es soberana... Pasó un año más y ella se casó nuevamente. (Pausa). Y a mí, aun convencido del perfecto derecho a esa boda, me parecía que el mundo se me caía encima y enfermé de rabia y de tristeza, sin atreverme ni a salir a la calle, por el temor a encontrarme con ellos. DOCT. Eso traen las leyes. ANTO. Si las otras no trajeran esto, escogería las otras. Pero son peores. Aquellas dan una vergüenza y un dolor de un día... de un año... ¡Estas lo dan eternamente!» (Linares Rivas, 1999e: 1946-1947). 
sus legítimos herederos ${ }^{21}$. En Todo Madrid lo sabía... (1931) sucede algo similar, la ambigua ley de funcionarios deja en el aire las prestaciones por enfermedad, lo cual compromete la subsistencia de la familia protagonista ${ }^{22}$. En Fausto y Margarita (1935), si bien no aparece de manera explícita, se deduce una crítica a las leyes que no protegen al trabajador de las trampas de su patrón, ya que Samuel se vale de vacíos legales para extorsionar a Fausto. La fuerte presencia de lo legal constituye el estilema más reconocible de Linares Rivas.

\section{Conclusiones}

En este trabajo se han analizado los temas presentes en algunas de las obras de Manuel Linares Rivas: Aire de fuera (1903), Lo posible (1905), En cuarto creciente (1905), Clavito (1910), La fuerza del mal (1914), La garra (1914), La mala ley (1923), Todo Madrid lo sabía... (1931), Fausto y Margarita (1935) y El error del capitán Rubín (1935). Como se exponía en la introducción, el primer objetivo de este trabajo era responder la siguiente pregunta: ¿cuáles son los temas que presenta el teatro de Linares Rivas? El más recurrente es la opresión socioeconómica, especialmente representada por los personajes femeninos. Los ejemplos claros son Aire de fuera (1903), La garra (1914) o Fausto y Margarita (1935). En obras más breves, esta opresión se combate con la liberación sexual y emocional, tanto de la mujer como del varón, ambos oprimidos por el decoro, como se muestra en Lo posible (1905), en En cuarto creciente (1905) o en Clavito (1910). También es relevante el tema de las «dos Españas», donde se contrapone la España moderna y científica a aquella otra tradicional y oscurantista. Puede verse con especial intensidad en Aire de fuera (1903) y en La garra (1914). La crítica al materialismo burgués se puede encontrar fácilmente en Clavito (1910) y en La mala ley (1914). A Linares también le preocupa la tiranía que subyuga a los débiles, como se puede ver en La fuerza del mal (1914). Por último, lo legal supone una matriz temática, ya que es su visión del mundo como abogado progresista la que genera sus preocupaciones literarias.

Era también objetivo de este trabajo indicar hasta qué punto Linares Rivas se muestra comprometido con los colectivos más oprimidos. Como se ha podido observar, los temas no están tratados desde un punto de vista marxista. Linares Rivas no es un autor revolucionario, no aboga por la colectivización de los medios de producción, no pretende eliminar las clases sociales, ni es preocupación suya la alienación de la fuerza productiva del obrero. Sin embargo, al mismo tiempo resultan distantes de los «alfilerazos» (Mainer, 1972) lleva-

${ }^{21}$ Así expresa Lorenzo de la Hermida el motivo del conflicto dramático: «que hereden, sí, muy bien...; pero que hereden a los muertos y no a los que aún viven; que eso no es heredar, sino despojar. Y la ley inicua, la mala ley es la que otorga derecho para reclamar la herencia de los padres mientras uno de ellos vive todavía» (Linares Rivas, 1927: 53)

${ }^{22} \mathrm{El}$ conflicto entre el estado y la familia viene resumido por Marcelina al final de la obra: «Durante ese tiempo se establece un diálogo chistosísimo entre el Estado y la enfermedad, El estado: "Ya te concedí dos meses de licencia con todo el sueldo". La enfermedad: "Pero yo voy a durar más”. El estado: "Bueno, otro mes, ipero a medio sueldo, eh!’. La enfermedad: "Pero yo voy a durar más...” ¡Esto es demasiado para la roñosería gubernamental y no lo quiere ni oír! ¡Arréglate como puedas que bastante hacemos reservándote la plaza! (Linares Rivas, 1931: 53). 
dos a escena por los dramaturgos innovadores. Esta técnica, atribuida mayormente al teatro de Jacinto Benavente, consistía en poner sobre las tablas críticas sociales fáciles de compartir (Oliva, 2002). El compromiso de Manuel Linares Rivas generó polémica entre la nobleza, la gran burguesía y los intelectuales más tradicionales de su época. Asimismo, resulta bastante próximo a autores novadores como Benito Pérez Galdós o Joaquín Dicenta. Ambos autores mostraban las miserias más arraigadas en la sociedad de su tiempo a través de postulados ideológicos progresistas, presentando temas como la opresión socioeconómica, las «dos Españas» o la mujer rupturista.

Una vez alcanzados los objetivos propuestos en la introducción, se puede concluir que la hipótesis de partida que sostiene que Linares Rivas pertenece a la tendencia novadora es una base solvente para continuar esta línea de investigación. Este trabajo está limitado al estudio de diez obras teatrales, lo que supone solamente una pequeña muestra de toda su labor artística. Recuérdese que Linares Rivas escribió al menos 104 obras teatrales, 35 obras narrativas y una amplia nómina de artículos y ensayos todavía por clasificar. En trabajos futuros se aumentará el corpus para matizar más el papel cultural que Linares Rivas desempeñó durante toda su labor intelectual a través de las décadas.

\section{BIBLIOGRAFÍA}

Aguado, Ana (2011), «Familia e identidades de género. Representaciones y prácticas (1889-1970)», en Chacón, Francisco y Joan Bestard (ed.), Familias. Historia de la sociedad española (del final de la Edad Media a nuestros días), Madrid, Cátedra, págs. 743-808.

Aub, Max (1974), Manual de historia de la literatura española, Madrid, Akal.

Berenguer, Ángel (1982), «El teatro en el siglo XX (hasta 1936)», en Díez Borque, José María (coord.), Historia de la literatura española, Madrid, Taurus, vol. 4, págs. 7-87. Primera edición en 1980.

Brown, Gerald (1974), Historia de la literatura española. Siglo XX, Barcelona, Ariel. Publicación original: Brown, Gerald (1972), A Literary History of Spain. The Twentieth Century, New York, Barnes and Noble.

Castellón, Antonio (1994), El teatro como instrumento político en España (1895-1914), Madrid, Endymion.

Castro López, Moisés (2001a), «Planteamientos sociales en El caballero lobo, de Linares Rivas», en Castro López, Moisés et al., Actas. I Congreso Estudiantil de Literatura Española Contemporánea, A Coruña, Universidade da Coruña, págs. 81-84.

- (2001b), «El tándem Linares Rivas-Reparaz y la inspiración de La viuda alegre», en CASTRo LóPEZ, MoIsés et al., Actas II congreso estudiantil de literatura española contemporánea, A Coruña, Universidade da Coruña, págs. 223-229.

- (2003), «Linares Rivas o un hombre de teatro a través de sus memorias», en Castro López et al., Estudios sobre literatura española contemporánea, A Coruña, Universidade da Coruña, págs. 27-31.

- (2008), «La vida teatral en A Coruña y biografía de M. Linares Rivas. 1902: El Noroeste (2º cuatrimestre)», en Castro López, Moisés et al., Haz de luz. Estudios de literatura contemporánea, A Coruña, Universidade da Coruña, págs. 159-169.

Díez Figueroa, Rebeca (200 I), «La espuma del champagne, de Linares Rivas: dos maneras de hacer teatro», en López Criado, Fidel (coord.), El papel de la literatura en el siglo xx. I Congreso Nacional Literatura y Sociedad, A Coruña, Universidade da Coruña, págs. 295-311. 
- (2005), «Mujer, progreso y república en el teatro de Manuel Linares Rivas», en López Criado, Fidel (ed.), La república de las letras y las letras de la república. Estudios de literatura española contemporánea, A Coruña, Ayuntamiento de A Coruña, págs. 205-210.

García Freire, Ana María (200I), «La mujer en el teatro de Linares Rivas: Primero, vivir...», en López Criado, Fidel (coord.), El papel de la literatura en el siglo XX. I Congreso Nacional Literatura y Sociedad, A Coruña, Universidade da Coruña, págs. 281-294.

- (2005), «El drama de la emigración: ¡Mal año de lobos...! de M. Linares Rivas», López Criado, Fidel (ed.), La república de las letras y las letras de la república. Estudios de literatura española contemporánea, A Coruña, Ayuntamiento de A Coruña, págs. 315-322.

- (2009), «La heroicidad femenina en el teatro de Manuel Linares Rivas», en López Criado, Fidel (ed.), Héroes, mitos y monstruos en la literatura española contemporánea, Santiago de Compostela, Andavira, págs. 87-94.

García López, José (I962), Historia de la literatura española, Barcelona, Vicens Vives.

Huerta Calvo, Javier y Emilio Peral Vega (2003), «Benavente y otros autores», en Huerta Calvo, Javier (dir.), Historia del teatro español, Madrid, Gredos, vol. 2, págs. 2271-2310.

Larra, Mariano José DE, «El día de difuntos de 1836. Fígaro en el cementerio», en Biblioteca Virtual Miguel de Cervantes, en línea: <http://bit.ly/2Bxjd5r> (última consulta: 10/02/2020). Publicación original en El Español, núm. 368, 02/11/1836.

Linares Rivas, Manuel, Clavito (I9Io), Madrid, Sociedad de Autores Españoles.

- (1918), Lo posible, Madrid, La Novela Cómica.

- (1927), La mala ley/ Primero, vivir..., Madrid, El Teatro Moderno, págs. 2-75.

- (1928), En cuarto creciente/ Señor Sócrates, Madrid, El Teatro Moderno, págs. 7-34.

- (1931), Todo Madrid lo sabía..., Madrid, La Farsa.

- (1999a), Fausto y Margarita, en López Criado, Fidel, El teatro de Manuel Linares Rivas, A Coruña, Diputación de A Coruña, vol. 1, págs. 329-388.

- (1999b), El error del capitán Rubín, en López Criado, Fidel, El teatro de Manuel Linares Rivas, A Coruña, Diputación de A Coruña, vol. 1, págs. 391-455.

- (1999c), Aire de fuera, en López Criado, Fidel, El teatro de Manuel Linares Rivas, A Coruña, Diputación de A Coruña, vol. 2, págs. 1066-1118. Publicación original en Madrid, El Teatro Moderno, 02/06/1928.

- (1999d), La fuerza del mal, en López Criado, Fidel, El teatro de Manuel Linares Rivas, A Coruña, Diputación de A Coruña, vol. 3, págs. 1851-1913. Publicación original en Madrid, El Teatro Moderno, 07/08/1926.

- (1999e), La garra, en López Criado, Fidel, El teatro de Manuel Linares Rivas, A Coruña, Diputación de A CoRUÑA, vOL. 3, págs. 1915-1965. Publicación original en Madrid, El Teatro Moderno, 12/12/1925.

López CRiado, Fidel ( I996), «La mujer nueva y el nuevo siglo en el teatro de Linares Rivas», en Blesa, Túa (ed.), Mitos. Actas del VII Congreso Internacional de la Asociación Española de Semiótica, Zaragoza, Asociación Española de Semiótica, vol. 2, págs. 793-799.

- (1997a), «Fausto y su circunstancia: el teatro de Manuel Linares Rivas», en Gómez Blanco, Carlos J., (coord.), Literatura y cine: perspectivas semióticas: Actas del I Simposio de la Asociación Galega de Semiótica (celebrado en La Coruña los días 6, 7 y 8 de abril de 1995), A Coruña, Universidade da Coruña, págs. 227-244.

- (1997b), «El teatro de Manuel Linares Rivas: un Fausto desconocido», España contemporánea. Revista de literatura y cultura, tomo 10, núm. 1, págs. 55-74.

- (1998), «El caso de Linares Rivas: exhumación de una obra maldita», Teatro: revista de estudios teatrales, núm. 13-14, págs. 71-93.

- (I999), El teatro de Manuel Linares Rivas, A Coruña, Diputación de A Coruña. 
- (2001), «Éxodo, libertad y progreso en el teatro social de Manuel Linares Rivas», Anuario de estudios filológicos, vol. 24, págs. 273-284.

- (2009), «La mitología progresista en el teatro social español de primer tercio del siglo XX», en López Criado, Fidel (ed.), Héroes, mitos y monstruos en la literatura española contemporánea, Santiago de Compostela, Andavira, págs. 27-40.

- (2014), «La ley, la moral y el decoro en el teatro feminista del primer tercio del siglo xx», Acta literaria, NúM. 48, págs. 117-137.

MaINer, José CARlos (I972), Literatura y pequeña burguesía en España (notas 1890-1950), Madrid, Cuadernos para el diálogo.

- (20io), Historia de la literatura española. Modernidad y nacionalismo (1900-1936), Barcelona, Crítica.

Oliva, CÉSAR (2002), Teatro español del siglo xx, MAdrid, Síntesis.

Rodríguez CACHO, Lina (2009), Manual de historia de la literatura española 2. Siglos XVIII al XX [hasta 1975], Madrid, Castalia.

Rodríguez LóPeZ-VÁzQuez, Alfredo (I995), «La trilogía del adulterio de Linares Rivas: notas para una didáctica del teatro breve», Lenguaje y textos, núm. 6-7, págs. 27-40.

Ruiz Ramón, Francisco (i986), Historia del teatro español. Siglo xx, Madrid, Cátedra.

VÁzQuez de Prada, Mercedes (2005), «Para una historia de la familia española en el siglo XX», Memoria y civilización, núm. 8, págs. 115-170.

Villarías Zugazagoitia, José María (200I), «El polémico estreno en Madrid de La garra», Letras de Deusto, Bilbao, Universidad de Deusto, vol. 31, núm. 90, págs. 103-125. 